\title{
The Prevention and Control of HIV/AIDS, TB and Vector-borne Diseases in Informal Settlements: Challenges, Opportunities and Insights
}

\author{
Annette M. David, Susan P. Mercado, Daniel Becker, \\ Katia Edmundo, and Frederick Mugisha
}

\begin{abstract}
Today's urban settings are redefining the field of public health. The complex dynamics of cities, with their concentration of the poorest and most vulnerable (even within the developed world) pose an urgent challenge to the health community. While retaining fidelity to the core principles of disease prevention and control, major adjustments are needed in the systems and approaches to effectively reach those with the greatest health risks (and the least resilience) within today's urban environment. This is particularly relevant to infectious disease prevention and control. Controlling and preventing HIV/AIDS, tuberculosis and vector-borne diseases like malaria are among the key global health priorities, particularly in poor urban settings. The challenge in slums and informal settlements is not in identifying which interventions work, but rather in ensuring that informal settlers: (1) are captured in health statistics that define disease epidemiology and (2) are provided opportunities equal to the rest of the population to access proven interventions. Growing international attention to the plight of slum dwellers and informal settlers, embodied by Goal 7 Target 11 of the Millennium Development Goals, and the considerable resources being mobilized by the Global Fund to fight AIDS, TB and malaria, among others, provide an unprecedented potential opportunity for countries to seriously address the structural and intermediate determinants of poor health in these settings. Viewed within the framework of the "social determinants of disease" model, preventing and controlling HIVIAIDS, TB and vectorborne diseases requires broad and integrated interventions that address the underlying causes of inequity that result in poorer health and worse health outcomes for the urban poor. We examine insights into effective approaches to disease control and prevention within poor urban settings under a comprehensive social development agenda.
\end{abstract}

KEYWORDS Communicable disease prevention and control, Dengue fever, HIV/AIDS, Informal settlements, Malaria, MDG, Slums, Social determinants, Tuberculosis, Urban health, Urbanization.

\section{INTRODUCTION}

Most cities in the developing world are poorly equipped to handle the ecological and social pressures brought on by rapid urban population increase and its

David is with the Health Partners, L.L.C., Tamuning, GU, USA; Mugisha is an Associate Research Scientist, African Population and Health Research Centre, Nairobi, Kenya; Becker and Edmundo are with the Centro de Promoçao da Saúde, Rio de Janeiro, Brazil; Mercado is with the Urbanization and Health Equity Focus, WHO Kobe Centre, Kobe, Japan.

Correspondence: Annette M. David, Health Partners, L.L.C., Tamuning, GU, USA. (E-mail: amdavid@guamcell.net) 
attendant consequences. Urban population growth without economic development is largely responsible for the association of urbanization with impoverishment. ${ }^{1}$ Poverty is increasingly shifting from rural to urban areas; the 'urbanization of poverty' ${ }^{2}$ has profound implications for disease epidemiology and public health practice. This is particularly evident for communicable diseases.

Conditions typically associated with infectious disease epidemics, such as increased population growth and mobility, crowding, ineffective regulatory structures inhibiting effective public health interventions, and ecologic and environmental changes that disrupt the traditional boundaries separating microbes and humans, are very similar to the conditions that characterize rapid urbanization in the absence of concomitant economic development. Thus, rapid urbanization in less developed settings invariably is accompanied by the resurgence of "old" epidemics and the emergence of "new" infectious diseases. ${ }^{3}$ Many of these diseases, including HIV/AIDS, tuberculosis and malaria, are often considered as "diseases of poverty" in that incidence, mortality rates and burden of disease are higher in less developed countries. In addition, malaria and dengue are water-related vectorborne diseases, and global evidence supports a direct and consistent association between access to clean water and poverty levels. ${ }^{4}$

The integral role of health in human development and, in particular, the important links between HIV/AIDS, tuberculosis and malaria to poverty ${ }^{5}$ are validated by the inclusion of each of these issues in the Millennium Development Goals (MDGs). ${ }^{6}$ The MDGs also have a specific target (Goal 7, Target 11) to "significantly improve the lives of at least 100 million slum dwellers by 2020".?

Informal settlements are the visible manifestation of poverty at its most extreme, and it follows that if impoverishment, as a structural determinant of health, confers greater risks for exposure and vulnerability to disease through social inequity, then informal settlers possess the greatest risks and are the most vulnerable to HIV/AIDS, tuberculosis and vector-borne diseases. Within this context, delineating the social determinants of health within poor urban settings is crucial.

Using the proposed "comprehensive social determinants of health model" developed by the Commission on Social Determinants of Health, ${ }^{8}$ this paper provides an initial account of some of the key issues to be considered in the prevention and control of Human Immunodeficiency virus/Acquired Immunodeficiency Syndrome (HIV/AIDS), tuberculosis (TB) and vector-borne diseases, particularly malaria and dengue fever, within the context of improving health and building human capital in urban informal settlements.

\section{METHODOLOGY}

A web-based search was conducted to identify a cross-section of studies and papers that related HIV/AIDS, tuberculosis, malaria and dengue to the key concepts of poverty, urbanization, slums and informal settlements. Both academic (PubMed/ Medline and Bids) and popular search engines (Google) were used, to ensure inclusion of "grey literature" as well as work conducted outside of the clinical/ health sector. An exhaustive review was not possible due to time constraints, but effort was taken to review work representing the perspectives of the multiple sectors involved in the control and prevention of infectious diseases within urban settings.

The websites of international agencies and organizations, known for their work in the areas of urban health were examined, and links to potentially useful material were followed up. References were solicited from colleagues working in the area of urban 
health. In addition, information from colleagues involved in field implementation of relevant projects was obtained through face-to-face, telephone or electronic interviews.

The authors, selected to represent the three regions that carry the greatest burden of HIV/AIDS, tuberculosis and vector-borne diseases (Africa, Central and South America, and Asia-Pacific), brought a broad range of perspectives when reviewing the collected information. Using a process similar to grounded theory inquiry, within the framework of the "social determinants of health model," common "themes" were delineated and synthesized to create the insights and recommendations of this paper.

\section{THE FIRST CHALLENGE: A BILLION SILENT VOICES}

Global databases consistently demonstrate the higher incidence, prevalence, mortality and burden of HIV/AIDS, tuberculosis and vector-borne diseases in developing countries. $^{9,10}$ Of the 40 million people infected with HIV, 95\% live in developing countries. Sub-Saharan Africa is the hardest hit, accounting for $75 \%$ of all HIV/AIDS cases and over $75 \%$ of all HIV/AIDS deaths. ${ }^{11}$ Similarly, malaria, prevalent in 105 countries and territories, kills more people in Sub-Saharan Africa than in any other region of the world. ${ }^{11}$ Low- and lower-middle-income countries account for more than $90 \%$ of TB cases and deaths. Southeast Asia has the largest burden, but SubSaharan Africa is rapidly catching up, largely due to the synergy between infection with HIV and TB. ${ }^{12}$ Of interest, Sub-Saharan Africa and Asia account for $75 \%$ of the world's urban poverty, and Sub-Saharan Africa has the highest estimated percentage $(71.9 \%)$ of the urban population classified as informal settlers. ${ }^{13}$

At the national and sub-national level, some data is available, disaggregated for urban vs. rural areas. ${ }^{14}$ What is not readily available is data on HIV/AIDS, tuberculosis and vector-borne diseases in urban areas disaggregated for formal vs. informal settlers. When it comes to disease statistics, the "billion voices" of informal settlers across the world are silent. The paucity of disaggregated urban data on informal settlers represents the first challenge in the prevention and control of these diseases within informal settlements. Further, disaggregated urban data (such as from intra urban health differentials studies) would be useful to highlight the inequities between communities.

Aggregate urban statistics may mask glaring health inequalities under the appearance of an "urban health advantage."13,15,16 Breaking down urban health data often reveals many intra urban health differences. Four recent South African studies have found that the HIV prevalence of those living in urban informal areas is double that of formal urban settlements. ${ }^{17}$ Children living in a squatter area are nine times more likely to have tuberculosis than non-squatter children in Manila, Philippines. ${ }^{18}$ In the Bronx, New York City, children are five times more likely to contract TB than their wealthier neighbours. ${ }^{19}$ Urban statistics that fail to reveal these intra urban health differentials may cause city planners to overlook health resource, infrastructure and service delivery needs of informal settlements.

Among the urban poor, gradients of disadvantage exist. Gender is a major cross-cutting structural determinant of health and poor urban women generally exhibit higher risks for disease and poorer overall health status than poor urban men. At the individual level, gender inequality renders many poor women less able to negotiate safe sexual relations than their male partners, leaving the women more vulnerable to HIV/AIDS. ${ }^{20,21}$ At the institutional level, gender inequality compounds differences in quality of care for poor urban women. Tuberculosis causes more deaths among women of reproductive age than any other infectious disease, ${ }^{22}$ yet, all other factors being equal, the health care system in Vietnam is less likely to 
test and treat women for TB than men. ${ }^{23}$ Furthermore, health inequalities persist within vulnerable groups. ${ }^{13,24}$ For example, female sex workers are more disadvantaged than other urban poor women, because the nature of their work makes them even less able to demand that their partners use condoms.

International agencies and a number of countries have begun to address the gap in baseline data on the urban poor using a variety of approaches that utilize estimation methodology on existing datasets, ${ }^{13}$ re-analyze existing data disaggregated by various measures of poverty ${ }^{25,26}$ or create community profiles of slums through participatory data collection. ${ }^{27}$ When sufficient data is available at the subcity level, visual mapping and spatial statistical analysis is possible using Geographic Information System (GIS). The GIS maps can serve as an essential visual tool to understand slum dynamics, assess urban poor conditions and inform local urban policy planning. ${ }^{28}$ These efforts represent a positive first step towards understanding and responding to the relative health disadvantages of informal settlers in relation to HIV/AIDS, TB and vector-borne diseases.

However, to make a meaningful impact on the prevention and control of these infectious diseases in informal settings, a systematic cross-country approach standardizing the collection of key indicators within informal settlements and integrating data collection into a regular surveillance system is critical. This will require fundamental shifts in urban policy and data collection systems at multiple levels. At the political level, both national and municipal governments will need to officially acknowledge informal settlements as a recognized classification of human settlements, in addition to the existing urban-rural scheme. At the health systems level, data on HIVIAIDS, TB and vector-borne diseases should be disaggregated consistent with the revised system of classifying human settlements. This implies that spatial disaggregation of data along formal and informal strata will become normative in urban statistics. The previously "invisible cities" (informal settlements), often omitted from official maps and documents and excluded from urban governance and health systems planning, will be uncovered, counted, monitored over time and acknowledged in urban decision-making and health resource allocation on an ongoing basis.

\section{THE SECOND CHALLENGE: ENSURING AVAILABILITY, ACCESS AND AFFORDABILITY OF EVIDENCE-BASED INTERVENTIONS TO PREVENT, CONTROL, AND DEAL WITH THE IMPACT OF HIV/AIDS, TUBERCULOSIS AND VECTOR-BORNE DISEASE IN INFORMAL SETTLEMENTS}

The body of peer-reviewed literature documenting the effectiveness (including costeffectiveness) of preventive and control measures for HIV/AIDS, tuberculosis and vector-borne diseases is substantial. ${ }^{9}$ The challenge for infectious disease control in informal settlements is not in identifying which interventions work, but rather in ensuring that the urban poor have opportunities equal to the rest of the population to access proven interventions. This is formidable, given that the political, social and economic conditions, which diminish access for informal settlers, are oftentimes the same conditions that give rise to informal settlements in the first place.

Informal settlements can be considered the "worst case" outcome of the social determinants of health model. Informal areas arise out of a socio-political context that fosters urban stratification based on differential access to power and resources. Within this context, informal settlers have little or no power, and extremely limited 
resources. Not surprisingly, informal settlers have some of the highest risks for HIV/ AIDS, TB and vector-borne diseases, through increased exposure to disease agents (e.g. overcrowding facilitates exposure to the TB bacilli) and greater vulnerability to infection (e.g. malnutrition impairs the immune system and lowers resistance to HIV). Once infected, their capacity to cope with the consequences of disease is diminished because of barriers to access preventive, diagnostic and curative services. For instance, when entry into the public health system requires proof of residence, informal settlers, who have no official address, are immediately excluded. The urban poor may not be able to reach health care centers if public transportation routes by-pass their communities because of poor urban planning.

Efforts to prevent and control HIV/AIDS, TB and vector-borne diseases in slums and informal settlements are not likely to succeed outside of an integrated approach that seeks to reduce the underlying social inequities that: (1) predispose slum dwellers to these infectious diseases and (2) confer on them a relative disadvantage in accessing health services. Such an approach requires significant multisectoral effort and resource mobilization, and is beyond the capacity of the health sector to address, by itself. However, within the health system, pro-poor measures can significantly improve access to health services at all stages of care seeking.

Recognizing this, the health sector should institute actions to minimize barriers for the poor. These include enhancing access by bringing health services into the community and/or workplace (e.g. workplace-based Directly Observed Treatment Short course, or DOTS, community-based home care for persons with HIV/AIDS), the "close-to-client" (CTC) approach; ${ }^{29}$ advocating for the elimination of user fees for primary health care in the public sector; encouraging pro-poor public-private partnerships for preventive and treatment services; reducing stigma through information dissemination and advocacy; incorporating gender-sensitive approaches to patient education and treatment; and addressing health systems barriers through enlightened policies and practices that do not discriminate against the poor.

Financial barriers are among the most critical in denying these individuals access to timely health care services. Addressing the financial barriers at the institutional level requires local governments and countries to consider a variety of mechanisms. Government subsidies on food staples are well known, but some countries, condoms, insecticide-treated bed nets and medicines used for DOTS, antiretroviral therapy and artemisinin combination therapy are partially or fully subsidized by the government. Subsidized health care is an important health promotion strategy in these settings, through direct provision of services, subsidized health insurance for families below an income cutoff, or a combination of both.

Community financing schemes where governments match community contributions into a common fund would cover basic curative services outside of essential health services already provided by the government through its regular budgetary allotment. ${ }^{30}$ These financing schemes have the potential to provide significant protection and extended access to a large number of low-income populations, and need to be scaled up systematically in the developing world. ${ }^{28}$

Consistent with the "social determinants of health" model, comprehensive health measures to improve access to proven interventions to HIV/AIDS, TB and vector-borne diseases can be viewed as poverty reduction strategies, because they enhance the urban poor's human capital by improving their health. The converse is equally vital: social empowerment and poverty reduction can boost the capacity of informal settlers to combat these communicable diseases. A good example is the RADAR initiative in South Africa, which has successfully linked socioeconomic 
empowerment of women to HIV prevention initiatives. ${ }^{31}$ Thus, health interventions need to be complemented by efforts that extend beyond the health care system, through an integrated development agenda that incorporates health interventions into programmes designed to ultimately address the root causes of social inequity and poverty.

\section{THE THIRD CHALLENGE: CREATING REAL HEALTH IMPACTS FROM POTENTIAL OPPORTUNITIES}

Developments at the global level are providing unprecedented potential opportunities to achieve measurable and significant health gains in informal urban settings. Global recognition of the complex and pivotal interrelationship of health and poverty has led to enlightened policies that integrate health interventions into the global development agenda. The MDGs represent the culmination of efforts by the United Nations and other international agencies to delineate a common road map for achieving optimal human development. In this road map, health is placed "at the heart of development." 32 Three of the eight goals, eight of the 18 targets, and 18 of the 48 indicators of progress are health-related. In addition, the MDGs specifically address quality of life improvements for informal settlers.

In turn, this has revitalized resource mobilization for key health concerns. The Global Fund to fight AIDS, tuberculosis and malaria was created in 2002 and directly responds to MDG Goal $6 .{ }^{33}$ Other initiatives and partnerships augmenting technical support to countries include the STOP TB initiative, the Roll Back Malaria initiative, the Joint United Nations Programme on HIV/AIDS (UNAIDS), the Global Alliance for Vaccines and Immunization (GAVI), the International AIDS Vaccine Initiative, the Medicines for Malaria Venture, the Global Alliance for Tuberculosis, and the Global Alliance for Improved Nutrition.

The third challenge in addressing HIV/AIDS, TB and vector-borne diseases in informal settlements is how to strategically utilize these potential opportunities to create real improvements in the urban poor's conditions so that they are better able to reduce their vulnerability to HIV/AIDS, TB and vector-borne diseases, and to access the full range of health care services to prevent, treat and mitigate these diseases. The global programmes created to mobilize resources for these diseases are generally very disease-oriented and vertically designed. Global health policy planners and funders of these programmes need to re-assess their structural focus and independent programmes of work, in light of the lessons emerging from countries regarding the importance of multi-sectoral, multi-level integrated approaches that frame HIV/AIDS, TB and vectorborne diseases within the "social determinants of health" model.

\section{MOVING FROM KNOWLEDGE TO ACTION: INSIGHTS AND EMERGING THEMES}

\section{Political Recognition of Informal Settlements as an Official Classification of Human Settlement is Fundamental to Address the Various Challenges in These Settings.}

Social exclusion, which is at the heart of all informal settlements, comes from being officially invisible. The first, extremely necessary, step in addressing the challenge of HIVIAIDS, TB and vector-borne diseases in informal urban areas is to grant these communities recognition, by acknowledging them as a form of human settlement. 
Doing so leads to enhanced surveillance systems that can disaggregate urban communities according to socio-economic variables. This is vital in establishing a baseline understanding of informal settlement dynamics, and in tracking progress in disease reduction/prevention within these settings. Often a lack of baseline maps is used to justify informal areas being excluded from demographic data collection. The use of aerial photographs can be a very useful way of making these communities visible to politicians, health planners and data collectors. ${ }^{34}$

More importantly, this move confers political status to informal dwellers, providing a mechanism to foster urban inclusiveness and integration into society. Recognition of informal settlements paves the way for local political attention and health resource allocation that are so vital to improve the condition of health settlers.

\section{Successfully Controlling and Preventing Infectious Diseases in Slums and Informal Settlements is Best Achieved Through a Holistic Approach Centered on a Social Development Agenda.}

Poor health outcomes of slum dwellers ultimately result from factors outside of the health care system. Health systems can address some of the intermediate determinants of health but are limited in their ability to impact on the broader sociopolitical, economic and cultural context within which health inequities emerge. Thus, the optimal approach is to embed or integrate HIV/AIDS, TB and vector borne disease control and prevention strategies within a more encompassing framework that addresses the root causes of poverty and differential opportunities. An important caveat is to recognize that for those countries with high prevalence rates of HIVI AIDS, TB and vector borne diseases, where human capital of slum dwellers is significantly diminished by these diseases, disease control becomes a de facto poverty alleviation strategy, and is the foundation for replenishing human capital.

Ideally, health interventions should be designed as a component of pro-poor, people-focused urban poverty reduction policies that link security of tenure, provision of basic services such as water, sanitation, etc. and livelihood opportunities to the provision of health services so that informal settlements can be transformed into viable, safe and healthy communities. This type of enlightened urban health policy is already operational in some parts of the world. WHO's Healthy Settings approach, as embodied in the Healthy Cities Alliance should be reexamined for opportunities for health promotion and prevention in poor urban settings. Urban planning also needs to be undertaken with a strong voice of the health sector. In this regard, re-aligning the various global programmes for HIV/AIDS, TB and vector-borne diseases from channeling large amounts of resources into very tightly focused, disease-oriented, vertical approaches towards a broader, more integrated developmental approach is needed urgently.

\section{An Effective Social Development Agenda, Including the Health Components, Requires the Full Participation and Involvement of the Urban Poor in Decision-Making, Planning, Development, Implementation and Evaluation.}

The urban poor should play a key role in the improvement of their living conditions. Their participation in all stages of a social development agenda is a fundamental human right. Thus, involving the poor through participatory approaches is an end, in and of itself, as a means to redress social exclusion, inequity and disempowerment. Social inclusion is the first step in the important process of transformation-as an 
entry point for capacity building, informal settlers can be empowered to rise above being disease hosts and targets for health interventions and instead become the driving force for disease control and prevention and addressing the impact of diseases such as HIV/AIDS in their communities.

Involving the urban poor is also instrumental in enhancing implementation effectiveness of urban public policies and programmes. By providing the opportunity for self-determination, policies and programmes can be redirected and adapted to better address issues within the local context.

Although impoverished, the urban poor possess social capital and social potential. Recognizing and tapping into the remarkable potential in these communities can augment public health infrastructure at the community level. When seen in this light, poor urban settings become "slums of opportunity and potential" rather than "slums of despair."13

\section{In Assessing the Impact of Disease Control and Prevention Within Informal Settlements, it is Important to Also Measure the Effect of These Interventions in Reducing Health Inequity and Addressing Some of the Underlying Social Determinants of Health.}

Within a social development framework, the ultimate indicator of success is when interventions that result in improved health also have a correspondingly positive impact on communities and individuals' socio-economic position, and vice-versa. Good evaluation systems need to capture the dynamics of this feedback loop to help developmental and health policy makers and programme managers better understand the complex dynamics of the social determinants of health in urban settings.

\section{Finally, While HIV/AIDS, TB and Vector Borne Diseases Pose \\ Serious Threats to the Physical Health and Social \\ Well-Being of the Urban Poor, These Diseases Can, Themselves, Become the Rallying Points for Community Mobilization and Self-Empowerment.}

The experience across different countries demonstrates how certain health hazards, such as HIV/AIDS, TB, malaria or dengue, can potentially mobilize the development of communities, their leaders, and their organizations. ${ }^{35}$ HIV/AIDS, in particular, is deeply entrenched in the political agenda of organized social movements. Diseases like HIV/AIDS are generally perceived as a social concern, which motivates communities to take collective action.

Social mobilization initiated by these "social" diseases provides entry points for other prevention and health promotion initiatives within communities. Equally important, diseases with a social dimension highlight the underlying inequities that are perpetuated by gender, socio-economic, ethnic and cultural biases, and can enlighten communities on the need to defend their fundamental right to equal recognition, opportunity and access to legal and formal institutions and public services.

\section{REFERENCES}

1. Cheru F. African Renaissance: Roadmaps to the Challenge of Globalization. London: Zed Books; 2002.

2. Annan K. Foreword. In: The Challenge of Slums Global report on Human Settlements 2003. London/Sterling, VA: Earthscan; 2006. 
3. Neubauer D. Globalization, Rapid Urbanization And Health Infrastructure. Santa Barbara, CA: UCLA Global Research Center, May 18, 2005. Available at: http:// www.globalization-africa.org/papers.php. Accessed September 20, 2006.

4. UN-Habitat. The Challenge of Slums Global report on Human Settlements 2003. London/Sterling, VA: Earthscan; 2006:11.

5. Bates I, Fenton C, Gruber J, et al. Vulnerability to malaria, tuberculosis, and HIV/ AIDS infection and disease. Part I: Determinants operating at individual and household level. Lancet Infectious Diseases [serial online]. 2004;4:267-277. Available at http:// infection.thelancet.com. Accessed September 20, 2006.

6. United Nations. United Nations Millennium Declaration. New York, NY: United Nations General Assembly; September 2000. Resolution A/55/2. Available at: http:// www.un.org/millennium/declaration/ares552e.htm. Accessed February 15, 2007.

7. United Nations. Millennium Development Goals, Targets, and Indicators. New York, NY: United Nations, 2002. DESA Technical Version.

8. Commission on the Social Determinants of Health. Towards a conceptual framework for analysis and action on the social determinants of health. Discussion paper for the Commission on Social Determinants of Health. Geneva, Switzerland: WHO, 2005:16-20.

9. Jamison DT, Breman JG, Measham AR, et al., eds. Disease Control Priorities in Developing Countries. 2nd ed. Washington, DC: Oxford University Press and the World Bank; 2006:289-309, 331-333, 414-417.

10. World Health Organization. Addressing Poverty in TB Control: Options for National TB Control Programmes. Geneva, Switzerland: World Health Organization; 2005:10-20.

11. UNAIDS. Report on the Global HIV/AIDS Epidemic. Geneva, Switzerland: World Health Organization; 2002.

12. Tuberculosis Fact Sheet 104. World Health Organization Web site. Available at: http:// www.who.int/mediacentre/factsheets/fs104/en/print.html. Accessed February 15, 2007.

13. UN-Habitat. Slums of the World: The Face of Urban Poverty in the New Millennium? [Working paper]. Nairobi, Kenya: The Global Urban Observatory; 2003:33-38.

14. UNAIDS/WHO Global HIV/AIDS Online Database [database online]. Geneva, Switzerland: World Health Organization; 2006. Updated 2007.

15. Todd A. Health inequalities in urban areas: a guide to the literature. Environ Urba. 1996;8:141-152.

16. Freudenberg N, Galea S and D. Vlahov Cities and the Health of the Public. Nashville: Vanderbilt University Press; 2006:11.

17. Community Contribution to TB Care. Geneva, Switzerland: World Health Organization; 2003:18

18. Fry S, Cousins B, Olivola K. Health of Children Living in Urban Slums in Asia and the Near East: Review of Existing Literature and Data. Washington, DC: Environmental Health Project, U.S. Agency for International Development; 2002.

19. World Resources Institute. World Resources 1996-1997: A guide to the Global Environment. Washington, DC: World Resources Institute, UNEP, UNDP, the World Bank: 1996.

20. Paiva V. Gendered scripts and the sexual scene. In: Parker R, Barbosa RM, Aggleton P, eds. Framing the Sexual Subject: The Politics of Gender, Sexuality and Power. Berkeley/ LA/London: University of California Press; 2000.

21. Paiva V. Beyond magic solutions: prevention of HIV and AIDS as a process of psychosocial emancipation. Divulgação para Saúde para Debate. 2003;27:192-203.

22. World Health Organization. A Human Rights Approach to Tuberculosis. Geneva, Switzerland: World Health organization; 2001:12-13.

23. Long NH, Johansson E, Lonnroth K, Erikkson B, Winkvist A, Diwan VK. Longer delays in tuberculosis diagnosis among women in Vietnam. Int J Tuberc Lung Dis. 1999; 3:388-393.

24. Rossi-Espagnet A, Goldstein GB, Tabibzadeh I. Urbanization and health in developing countries: a challenge for health for all. World Health Stat Q. 1991;44(4):186-244. 
25. Baker J, Schuller N. Analyzing Urban Poverty: A summary of Methods and Approaches. World Bank Web site, September 2004. World Bank Policy Research Working Paper 3399. Available at: http://siteresources.worldbank.org/INTURBANPOVERTY/Resources/ana lyzingurbanpoverty.pdf. Accessed January 26, 2007.

26. World Bank. 2002 World Bank Atlas. Washington, DC: World Bank; 2002.

27. Environmental Health Project, US Agency for International Development. Improving the health of the urban poor: Learning from the USAID experience. Washington, DC: USAID; 2004. Strategic Report 12.

28. Lanjouw P, Mistiaen J, Ozler B. Poverty Mapping in Urban Areas [online presentation]. World Bank Web site, 2002. Available at: http://info.worldbank.org/etools/bSPAN/ presentationView.asp?EID=331\&PID=655. Accessed 15 February, 2007.

29. Commission on Macroeconomics and Health. Macroeconomics and Health: Investing in Health for Economic Development. Geneva, Switzerland: World Health Organization; December, 2001. Report of the Commission on Macroeconomics and Health presented to the World Health Organization.

30. Preker AS, Carrin G. Health Financing for Poor People Resource Mobilization and Risk Sharing. Washington DC: The World Bank; 2004:69-92.

31. Pronyk PM, Kim JC, Hargreaves JR, et al. Integrating microfinance and HIV prevention-perspectives from a community randomised trial in rural South Africa. RADAR Website, 2002. RADAR IMAGE Working Paper No. 1. Available at URL: http://www.wits.ac.za/radar/Publications.htm. Accessed January 27, 2007.

32. World Health Organization. The World Health Report 2003-Shaping the Future. Geneva, Switzerland: World Health Organization; 2003:23.

33. Global Fund. Annual Report 2005. The Global Fund Website, 2005. Available at: http:// www.theglobalfund.org/EN/about/publications/annualreport2005/. Accessed September 16, 2006.

34. Hurskainen P and P Pellikka. Change detection of informal settlements using multitemporal aerial photographs-the case of Voi, SE Kenya. In Proceedings of the 5th AARSE conference (African Association of Remote Sensing of the Environment), October 18-21, 2004, Nairobi Kenya.

35. Edmundo K, et al. Network of communities in the fight against AIDS: local actions to address health inequities and promote health in Rio de Janeiro, Brazil. Promot Educ. 2005; Special edition 3(Suppl 1). 